\title{
Significant fall in stroke admissions in the Malopolska Voivodeship of Poland during the COVID-19 pandemic
}

\author{
Agnieszka Słowik ${ }^{1}$, Ryszard Nowak ${ }^{2}$, Tadeusz Popiela ${ }^{3}$ \\ ${ }^{1}$ Department of Neurology, Jagiellonian University Medical College, Krakow, Poland \\ ${ }^{2}$ Department of Neurology, Rydygier Specialistic Hospital, Krakow, Poland \\ ${ }^{3}$ Department of Radiology, Jagiellonian University Medical College, Krakow, Poland
}

Key words: stroke, pandemic, Covid-19, Poland

(Neurol Neurochir Pol 2020; 54 (5): 471-472)

\section{To the Editors:}

There is growing evidence indicating that the global coronavirus 2019 (Covid-19) pandemic is responsible for decreasing both the number of patients admitted for acute stroke and the number of patients with acute stroke treated by intravenous thrombolysis, mechanical thrombectomy, or both $[1,2]$.

Małopolska Voivodeship (MV) is located in southeastern Poland and has a population of 3.36 million, $8.85 \%$ of the country's population. In $\mathrm{MV}$, a very small proportion of patients with acute stroke are not hospitalised [3]. According to standard procedures, patients with acute stroke are admitted to the nearest stroke unit (of the 15-unit Stroke Network) in the region, where intravenous thrombolysis will be performed. Those fulfilling the criteria for mechanical thrombectomy are admitted to the Comprehensive Stroke Unit at the University Hospital in Krakow. The number of patients with acute stroke admitted to hospitals without neurological departments is now very small. In 2019, of 6,255 patients diagnosed with acute stroke in MV (according to ICD-10: I61, I62, I63, I64), 1,055 (16.9\%) received intravenous thrombolysis, and 155 (2.5\%) received mechanical thrombectomy.

The first case of Covid-19 in Poland was diagnosed on 4 March, 2020, and the country was locked down six days later. The number of people in MV diagnosed with Covid-19 by the end of May 2020 was 1,215. Of those, 397 (32.7\%) were hospitalised at the University Hospital, which is the only hospital in MV dedicated to treating Covid-19. In spite of the pandemic, the number of beds available in the Stroke Network was adequate. The four-step process of lifting restrictions due to Covid-19 began on 20 April, 2020.

We examined all stroke admissions from January to May 2020 inclusive. We found that stroke admissions between January and April decreased by $19.4 \%$ and admissions to Stroke Units decreased by $24.6 \%$. Furthermore, the percentage treated using intravenous thrombolysis decreased by $32 \%$ (Tab. 1). In May, when Covid-19 restrictions began to be lifted, we noted an increase in stroke admissions and in treatment with intravenous thrombolysis (Tab. 1).

Interestingly, the percentage treated with mechanical thrombectomy was 25\% lower between January and May $2020(n=74)$ compared to the same period in $2019(n=99)$.

During the Covid-19 pandemic, the number of stroke admissions and the number of patients treated with intravenous thrombolysis or mechanical thrombectomy during the lockdown period were significantly lower compared to the previous year.

We speculate that patients with relatively mild strokes avoided hospitalisation for fear of contracting COVID-19. Alternatively, the incidence of stroke might have decreased during the pandemic due to unrecognised factors related to lockdown rules.

To determine which of these possibilities is the more likely, the clinical characteristics of stroke patients admitted during the pandemic should be compared to those of patients admitted prior to the pandemic. 
Table 1. Stroke incidence and treatment by intravenous thrombolysis in Malopolska Voivodeship from January to May 2020 inclusive

\begin{tabular}{|c|c|c|c|c|c|c|c|}
\hline Variable & January & February & March & April & May & $\begin{array}{l}\text { Difference } \\
\text { between } \\
\text { January and } \\
\text { April } 2020\end{array}$ & $\begin{array}{c}\text { Difference } \\
\text { between } \\
\text { January and May } \\
2020\end{array}$ \\
\hline Number of strokes & 603 & 523 & 507 & 486 & 493 & $-19.4 \%$ & $-18 . .2 \%$ \\
\hline Number treated in the Stroke Network & 556 & 489 & 472 & 419 & 451 & $-24.6 \%$ & $-18.9 \%$ \\
\hline $\begin{array}{l}\text { Number treated with intravenous } \\
\text { thrombolysis }\end{array}$ & 97 & 98 & 77 & 66 & 76 & $-32.0 \%$ & $-21.6 \%$ \\
\hline $\begin{array}{l}\text { Percentage treated with intravenous } \\
\text { thrombolysis (\%) }\end{array}$ & 16.0 & 18.7 & 15.2 & 14.1 & 15.4 & - & - \\
\hline $\begin{array}{l}\text { Percentage treated with intravenous } \\
\text { thrombolysis in the Stroke Network (\%) }\end{array}$ & 17.4 & 20,0 & 16.3 & 15.8 & 16.9 & - & - \\
\hline
\end{tabular}

Ethical permissions: Ethical approval was not necessary for the preparation of this article.

Funding: This publication was prepared without any external source of funding.

Acknowledgement: We thank Mrs. Elżbieta Fryźlewicz-Chrapisinska, Director of the National Health Fund, Malopolska Regional Division, for supplying data on stroke incidence and treatment in Malopolska Voivodeship.

Disclosures: Dr Stowik reports receiving honoraria, lecture fees and serving on an advisory board for Bayer, Boehringer Ingelheim, Medtronic, Novartis and Biogen. Dr Nowak reports receiving honoraria and lecture fees from Novartis and Biogen.

\section{References}

1. Markus HS, Brainin M. COVID-19 and stroke-A global World Stroke Organization perspective. Int J Stroke. 2020; 15(4): 361364, doi: 10.1177/1747493020923472, indexed in Pubmed: 32310017.

2. Kansagra AP, Goyal MS, Hamilton S, et al. Collateral Effect of Covid-19 on Stroke Evaluation in the United States. N Engl J Med. 2020 [Epub ahead of print], doi: 10.1056/NEJMc2014816, indexed in Pubmed: 32383831.

3. Słowik A, Turaj W, Zwolińska G, et al. Stroke attack rates and case fatality in the Krakow Stroke Registry. Neurol Neurochir Pol. 2007; 41(4): 291-295, indexed in Pubmed: 17874336. 